\title{
EL PESIMISMO HISTÓRICO EN LA FILOSOFÍA DE DENIS DIDEROT
}

\section{Adrián Ratto*}

Resumen: Los especialistas suelen atribuir a Diderot una concepción pesimista de la historia. Si bien de las obras de madurez del editor de la Encyclopédie se desprende una oscura imagen del porvenir, producto entre otras cosas de su encuentro con Catalina II y de la influencia de Galiani, ese pesimismo parece no agotar sus reflexiones acerca de la historia. De los trabajos de la época anterior a su viaje a Rusia se desprende otra concepción de la historia, la cual, no obstante, no se confunde con las cándidas especulaciones acerca del futuro del marqués de Condorcet.

Palabras clave: Diderot, historia, progreso, pesimismo, escepticismo

Abstract: Specialists commonly ascribe to Diderot a pessimistic conception of history. While the mature work of the editor of the Encyclopédie conveys an obscure image of the future, resulting, inter alia, from his encounter with Catherine II and from Galiani's influence, such pessimism never appears to exhaust his reflections on history. His work prior to his trip to Russia reveals another perception of history wich, nevertheless, is clearly distinct from the Marquis of Condorcet's candid speculations about the future.

Key words: Diderot, history, progress, pessimism, skepticism

Al final del Supplément au voyage de Bougainville, libro escrito por Denis Diderot en 1772, " $A$ " le pregunta a "B": "dígame, chay que civilizar al

* Egresado de la carrera de Filosofía de la Universidad de Buenos Aires. Actualmente es becario doctoral de CONICET bajo la dirección del Dr. Daniel Brauer. Su investigación está ligada al problema de la relación entre providencia, progreso y decadencia en la filosofía de la Ilustración francesa. E-mail: ga_ratto@yahoo.com.ar. 
hombre o dejarlo a su instinto?". Si bien la respuesta de Diderot es ambigua, Émile Faguet no dudó en afirmar que Diderot "predica un retorno a la naturaleza"2. Según Faguet, Diderot adoptó una posición contraria a la civilización. El crítico no dudó en sostener incluso que existió una veta "mística", "sentimental" en el pensamiento del editor de la Encyclopédiè. En un sentido similar Jules Delvaille afirmó que Diderot hizo en 1772 "el elogio de la vida salvaje y primitiva de los habitantes de Tahiti" ". Diderot, dice Delvaille, "predica el retorno a la vida de los bosques". El crítico traza un paralelismo entre este trabajo de Diderot y "las páginas célebres de Rousseau contra la civilización" 5 .

Si bien es verdad que existen pasajes de la obra de Diderot que parecen apoyar una interpretación como la de Faguet, este tipo de lecturas ha sido superado ${ }^{6}$. Por otra parte, Diderot se aleja expresamente del primitivismo. En la Réfutation de l'ouvrage d'Helvétius sostiene con respecto a la sociedad civilizada: "yo no pienso como Rousseau que sea necesario destruirla..."7. En el mismo sentido se expresa en una reseña al libro Histoire de Russie de Lomonosoff al hablar acerca de la Rusia medieval: "digan lo que digan Jean-Jacques Rousseau y los fanáticos enemigos de los progresos del espíritu humano, resulta difícil leer la historia de los siglos bárbaros del pueblo que fuere, sin felicitarse por haber nacido en un siglo

${ }^{1}$ Diderot, Denis, Supplément au voyage de Bougainville, en CEuvres Complètes de Diderot (edición de Assézat-Tourneux. De aquí en adelante A.-T. Las traducciones son nuestras), Paris, Garnier Frères, vol. II, 1875, p. 246.

2 Faguet, Émile, Dix-huitième siècle: études littéraires, Paris, Société française d'imprimerie et de librairie, 1898, p. 9 (las cursivas son nuestras).

${ }^{3}$ Cfr. Ibid. p. 8.

${ }^{4}$ Delvaille, Jules, Essai sur l'bistoire de l'idée de progrès jusqu'a la fin du XV TII siècle, Paris, Alcan, 1910, p. 617.

${ }^{5}$ Ibidem.

${ }^{6}$ Cfr. Gay, Peter, The Enlightenment: an Interpretation. The Science of Freedom, New York, Norton, 1977, pp. 94 y ss; Frankel, Charles, The Faith of Reason, New York, King's Crown Press, 1948, pp. 86 y ss.

${ }^{7}$ Diderot, Denis, Réfutation de l'ouvrage d'Helvétius intitulé L'Homme, en A.-T., vol. II, 1875 , p. 431. 
ilustrado y en una nación civilizada. Esos filósofos apologistas de la ignorancia, deberían ser más claros ¿Nos quieren brutos? ¿Quieren que seamos animales estúpidos, sin ninguna regla, sin ninguna ley?" 8 . Sin embargo, si bien se han superado las interpretaciones primitivistas, los especialistas no dejan de atribuir a Diderot una concepción pesimista de la historia. No es ya el pesimismo de las visiones nostálgicas del pasado, sino el de la imagen cíclica del tiempo, según la cual se repiten constantemente el ascenso y el declinamiento de las naciones?.

El objetivo de este trabajo es mostrar que, si bien no existió en ningún momento en la obra de Diderot un optimismo ingenuo como el de Turgot o el de Condorcet, el pesimismo histórico no agota su pensamiento. Para alcanzar este objetivo, luego de (1) repasar aquellos trabajos en los que Diderot desliza una imagen oscura acerca del porvenir, se analizará (2) la relación entre Diderot y la obra de Pierre Bayle, la cual permite sacar a la luz las bases sobre las que se apoyan las reflexiones de Diderot respecto de la historia en la época de la Encyclopédie; y finalmente (3) se examinará el intercambio epistolar entre Diderot y Falconet, el cual muestra la distancia que separa a Diderot del pesimismo extremo en la primera parte de su obra.

\section{Diderot pesimista}

Entre 1773 y 1774 Diderot realiza un viaje a Rusia para visitar a la emperatriz Catalina II. La emperatriz unía a los ojos de Diderot el poder y

\footnotetext{
${ }^{8}$ Diderot, Denis, Histoire de Rusie, en A.-T., vol. XVII, 1876, pp. 495-496.

${ }^{9}$ Cfr. Ottaviani, Thierry, "L' «histoire» chez Diderot ", en Recherches sur Diderot et sur l'Encyclopédie, $\mathrm{N}^{\circ}$ 30, 2001, p. 83; Papin, Bernard, Sens et fonction de l'utopie tabitienne dans l'cuvre politique de Diderot, Oxford, The Voltaire Foundation, 1988, pp. 17 y ss.; Duchet, Michèle, Antbropologie et bistoire au siècle des Lumières, Paris, Albin Michel, 1995, pp. 432 y ss.; Vyverberg, Henry, Historical Pessimism in the French Enlightenment, Cambridge, Harvard University Press, 1958, pp. 198, 199; Krakeur, Lester, "Diderot and the Idea of Progress", en The Romanic Revien, N ${ }^{\circ} 29 / 2,1938$, pp. 151159.
} 
las ideas del siècle des Lumières ${ }^{10}$. Catalina II seguía las políticas del difunto Pedro el Grande, quien había intentado sacar a Rusia del aislamiento y acercarla a los valores de los estados de la Europa Occidental. Esto había generado la crítica de Rousseau en el Contrat Social a Pedro por introducir ideas extrañas en Rusia, lo cual provocó una repuesta de Voltaire en el artículo "Pierre le Grand et J. J. Rousseau" de su Dictionnaire philosophique". Diderot realizó una serie de trabajos a partir de sus encuentros con Catalina II, quien se decía seguidora de les philosophes ${ }^{12}$, y entre 1773-4 los reunió bajo el nombre Mélanges philosopbiques, bistoriques, etc. (compilados y publicados por primera vez por Tourneux, bajo el título de Diderot et Catherine II). En estos trabajos la historia aparece como una planta frágil que se debe cuidar para que no degenere demasiado pronto.

Mientras que Francia era, a los ojos de Diderot, una nación sobre la "pendiente de la decadencia", Rusia podía construir instituciones firmes, podía, si Catalina seguía un plan civilizatorio, construir sobre la "roca". Esto le aseguraría a Rusia un extenso tiempo de prosperidad, "cien siglos de felicidad", dice. Sin embargo, señala, "la roca se agrieta a la larga"13. El Plan d' une Université (1775), redactado en la misma época también muestra el pesimismo de Diderot. Allí Diderot insiste sobre la importancia de la educación para sacar a un pueblo de la barbarie y para solidificar sus instituciones: "instruir a una nación, es civilizarla, ahogar sus

10 La admiración de Diderot por Catalina II comienza cuando ésta le ofrece terminar en Rusia la Encyclopédie, que había sido suspendida en Francia. "¡Es en Francia, el país de la civilización, las ciencias, las artes, el buen gusto, la filosofía, donde uno es perseguido! $Y$ es desde lugares alejados, fríos y bárbaros que se nos tiende una mano", dice Diderot en una carta dirigida en 1762 a Mlle. Volland; en Diderot, Denis, Correspondance, en A.-T., vol. XIX, 1876, p. 146.

11 Voltaire en su Histoire de l'empire de Russie sous Pierre le Grand había elogiado a Pedro por su plan civilizatorio.

12 Acerca de la relación de los filósofos ilustrados franceses con Catalina II, véase Gorbatov, Inna, Catherine the Great and the French philosophers of the Enlightenment, Bethesda, Academica Press, 2006.

${ }^{13}$ Cfr. Diderot, Denis, Diderot et Catherine II, ed. Maurice Tourneux, Paris, Calman Lévy, 1899, p. 119. 
conocimientos, es devolverla al estado primitivo de barbarie" ${ }^{14}$. Sin embargo, desde las primeras líneas advierte:

los griegos fueron bárbaros, se instruyeron y su nación devino floreciente ¿Cuál es el estado actual de esa nación? Hoy es ignorante y bárbara. Italia fue bárbara, se instruyó y devino una nación floreciente ¿Cuál es el estado actual de esa nación? Hoy es bárbara. Tal fue la suerte de África y de Egipto y tal será el destino de los imperios en todos los lugares de la tierra y en todos los siglos por venir ${ }^{15}$.

Más pesimistas aún son sus Observations sur le Nakaz, escritas en 1774 (el Nakaz es un tratado de teoría política que la misma Catalina II escribió en 1767, inspirada en las teorías de Montesquieu y Beccaria, con el objetivo de reemplazar el código de leyes ruso vigente en ese momento). El temor al despotismo sobrevuela todas las Observations. En este trabajo escrito durante el regreso de su estadía en Rusia Diderot plantea, influido por Montesquieu $^{16}$, una y otra vez el problema del poder absoluto. Como bien remarca Venturi, el problema del despotismo asedia en esa época la filosofía de Diderot ${ }^{17}$. Ya no distingue entre buenos y malos monarcas absolutos. En las últimas páginas dice expresamente que la monarquía absoluta no se diferencia del despotismo, o que sólo lo hace formalmente (cabe recordar que si bien Catalina II desliza la idea de establecer cuerpos

${ }^{14}$ Diderot, Denis, Plan d'une Université, en A.-T., vol. III, 1875, p. 429.

${ }^{15}$ Ibidem. Para una interpretación diferente, véase Didier, Béatrice, "Quand Diderot faisait le plan d'une université", en Recherches sur Diderot et sur l'Encyclopédie, vols. 1819,1995, p. 87.

${ }^{16}$ Acerca de la relación de la última filosofía de Diderot con la de Montesquieu, véase Rebejkow, Jean-Christophe, "Diderot lecteur de l'Esprit des Lois de Montesquieu dans les Observations sur le Nakaz", en Studies on T'oltaire, $\mathrm{n}^{\circ} 319,1994$, pp. 295-312. Para una interpretación en otro sentido, véase Cotta, Sergio, "L'Illuminisme et la science politique: Montesquieu, Diderot et Catherine II", en Revue internationale d'bistoire politique et constitutionnelle, $\mathrm{N}^{\circ} 4,1954$, pp. 273-287.

17 Cfr. Venturi, Franco, "La vieillesse de Diderot", en Recherches sur Diderot et sur l'Encyclopédie, $\mathrm{N}^{\circ} 12,1992$, p. 15. 
que limiten el poder del soberano en sintonía con las ideas de l'Esprit des lois, esos cuerpos dependerían de su poder, lo cual neutralizaría el freno). Donde el soberano dispone del poder a su placer, dice Diderot, "no hay ni derecho, ni ley, ni libertad”. Por estas razones ya en las primeras líneas afirma que el único soberano es el pueblo y en el segundo apartado dice que "la emperatriz de Rusia es una déspota"18.

Pero es, no obstante, en sus contribuciones a la obra de Raynal, Histoire philosopbique et politique des établissements et du commerce des Européens dans les deux Indes, particularmente en su tercera edición (1780), donde tomará mayor distancia del programa reformista de la Ilustración y de su idea progresiva del tiempo. Cabe señalar que para esa época Diderot no había solamente sufrido un desencanto respecto de Catalina II, sino que también había sido golpeado por el golpe de estado de Maupeou en 1771 y por el fracaso de Turgot en la función pública (Turgot fue finalmente destituido del cargo que le había asignado Luis XVI). Sin embargo todo esto no alcanza para explicar su pesimismo histórico. Es necesario añadir la influencia que sobre él había ejercido el abate Ferdinando Galiani.

Diderot conoció a Galiani en los años 60’ en los salones de Paris. Galiani devino uno de los amigos más cercanos a Diderot durante su estadía en Francia (1759-69). Sus ideas, en particular sus ideas económicas, presentadas en sus Dialogues sur le commerce des blés (1769), donde se critica la libre exportación de trigo en nombre del interés general, impactaron profundamente en el pensamiento del francés. Sin embargo, a los fines de este trabajo lo más significativo de la relación entre Diderot y Galiani es que a través de Galiani el francés toma contacto con las tesis de Giambattista Vico. Como señala Rosena Davison los trabajos de Galiani son

${ }^{18}$ Cfr. Diderot, Denis, Observations sur le Nakaz, en Diderot, Denis, Political Writings, (eds. John Hope Mason; Robert Wokler), Cambridge, Cambridge University Press, 1992, caps. VIII-XIV. 
indisociables de la filosofía del autor de Principi di una scienza nuova d'intorno alla commune natura delle nazioni $(1725)^{19}$.

En las obras de Galiani no sólo se reflejan la concepción de la naturaleza de Vico, diferente a la de les philosophes, y su realismo político, sino también su concepción de la historia, la teoría de los "corsi e ricorsi storici". Según esta teoría todas las naciones después de alcanzar un pico en su desarrollo recaen en la barbarie.

En este marco no es extraño escuchar a Diderot decir en su contribución a la Histoire que en todos los siglos se ha visto a las ciencias y las artes "nacer y morir" en un "orden regular"20. Esta regla, dice Diderot, vale para todas las sociedades, incluso "las más pobladas y las más esclarecidas". Asimismo en el libro XIX, luego de hablar del comienzo de las sociedades, de su necesario pasaje del estado salvaje al civilizado, dice:

lamentablemente ese estado es sólo momentáneo. Por todos lados las revoluciones en los gobiernos se suceden con una velocidad que apenas se puede seguir. Hay pocos estados que no las hayan sufrido y ninguno que con el tiempo no complete ese movimiento periódico. Más o menos todos siguen un círculo regular de pobreza y prosperidad, de libertad y esclavismo, de civilización y corrupción, de ilustración y de ignorancia, de grandeza y debilidad. La ley de la naturaleza, que quiere que todas las

${ }^{19}$ Cfr. Davison, Rosena, "Diderot, Galiani et Vico: un itinéraire philosophique", Diderot Studies, $\mathrm{N}^{\circ} 23,1988$, p. 40. Véase también Busnelli, Manlio, Diderot et l'Italie, Paris, Champion, 1925, p. 29.

${ }^{20)}$ Cfr. Raynal, Guillaume-Thomas, Histoire philosopbique et politique des établissements et du commerce des Européens dans les detix Indes, Genève, Pellet, vol. 3, 1780, libro XI, p. 128. No ha resultado fácil a los especialistas aislar la contribución de Diderot de la del resto de las personas que participaron en la Histoire. En la actualidad se cuenta con herramientas de gran utilidad como: Diderot, Denis, Pensées détachées. Contributions à l'Histoire des deux Indes, ed. Gianluigi Goggi, Università di Siena, Siena, 1976; Diderot, Denis, Melanges et morceaux divers: contributions a l'Histoire des deux Indes, ed. Gianluigi Goggi, Università di Siena, Siena, 1977; Diderot, Denis, Political W'ritings, eds. John Hope Mason y Robert Wokler, Cambridge, Cambridge University Press, 1992. En este trabajo seguimos este último texto. 
sociedades graviten hacia el despotismo y la disolución, que los imperios nazcan y mueran, no será suspendida por nadie" 21 .

No hay en este momento de la filosofía de Diderot una teoría del progreso: "en todos los siglos por venir el hombre salvaje avanzará paso a paso hacia la civilización y el hombre civilizado volverá a su estado primitivo"22.

En 1778 Naigeon encargó a Diderot una "vida de Séneca" para coronar la sexta traducción al francés de los trabajos del filósofo romano. El resultado es un relato complejo, articulado en diferentes niveles entre los cuales habría que distinguir a) el nivel expositivo de la filosofía de Séneca; b) la reconstrucción histórica de su época; c) el nivel autobiográfico, donde Séneca se convierte en Diderot y Nerón en Catalina II.

El trabajo, que fue publicado bajo el nombre de Essai sur Sénèque y que en 1782 fue reeditado bajo el nombre de Essai sur les règnes de Claude et de Néron, es mucho más que un simple "examen de conciencia" por haber aceptado la protección de una déspota como cree Wilson ${ }^{23}$. El Essai es la última puntada del giro que comenzó en la época de la lectura del trabajo de Galiani y del viaje a Rusia. A pesar de lo que dice Cassini ${ }^{24}$, el Essai no es otra cosa que una moral privada, una renuncia a la política y al porvenir. Diderot busca un refugio en una ética frente a un mundo ensombrecido por el despotismo, el fanatismo, la crueldad y la calumnia.

Diderot vuelve sobre la filosofía de Séneca luego de muchos años ${ }^{25}$ para reflexionar acerca del papel del filósofo en tiempos oscuros. Hace el

${ }^{21}$ Ibid., vol. 9, libro XIX, p 473.

22 Ibid, vol. 2, libro IX, p. 369.

${ }^{23}$ Cfr. Wilson, Arthur, Diderot: sa vie et son aurre, Paris, Robert Laffont, 1985, p. 578. 24 "El Essai sur Sénèca es algo más que una moral privada", en Cassini, Paolo, "Diderot apologiste de Sénèque", en Dix-buitième siècle, N 11, 1979, p. 248.

${ }_{25}$ Ya se había referido a ella, aunque en otros términos, en las anotaciones que hizo a su traducción del libro del conde de Shaftesbury, An Inquiry Concerning I'irtue or Merit (traducido en 1745 al francés por Diderot bajo el nombre Essai sur le mérite et la vertu). 
elogio de un hombre que dice la verdad a pesar de las sombras que lo rodean, de un hombre que "marcha con dignidad en medio de las calumnias y los insultos de ciudadanos que atacan su virtud y sus talentos" 26 . No sólo se refiere a Catalina II, sino también a los enemigos de la Encyclopédie, los jesuitas, Fréron y al mismo Rousseau.

Diderot no se condena al silencio, cree que siempre es posible "retrasar por lo menos algunos siglos el decreto pronunciado contra todas las cosas de este mundo; el cual las condena a tener su nacimiento, su tiempo de vigor, su decrepitud y su fin" 27 . Sin embargo, la batalla final está perdida. Como ya decía en 1767: "la felicidad de un individuo o de una nación tiene sus límites. Todas las cosas llevan en sí mismas el germen de la destrucción"28.

Bernard Papin afirma que Diderot no tuvo "ninguna intención de hacer del hombre primitivo el «buen salvaje» que su siglo había creído encontrar al fondo de los bosques"29. Por esta razón sostiene que la utopía tahitiana del Supplément au voyage du Bougainville no es en la obra de Diderot un programa político. Sin embargo, atribuye a Diderot una concepción organicista de la historia, la cual, si bien le permite tomar distancia del primitivismo, no lo aleja definitivamente del pesimismo histórico ${ }^{30}$. En un sentido similar, Arsenio Ginzo ubica la filosofía "organicista" de la historia de Diderot entre la de "los partidarios de una visión demasiado unidimensional del progreso y la de quienes propugnaban una visión primitivista excesivamente arcaizante" 31 , y Lester Krakeur señala que en la filosofía de Diderot las "civilizaciones florecen y declinan"

${ }^{26}$ Diderot, Denis, Essai sur les règnes de Claude et de Néron, en A-T., vol. III, 1875, p. 158.

${ }^{27}$ Ibid., p. 324.

${ }^{28}$ Diderot, Denis, Salon de 1767, en A-T., vol. XI, 1875, p. 93.

${ }^{29}$ Papin, Bernard, op. cit., p. 123.

${ }^{30}$ Ibid., p. 17.

${ }^{31}$ Ginzo, Arsenio, "Las aporías de la utopía. Progreso y primitivismo en Diderot", en Anales del seminario de Historia de la Filosofía, No 14, 1997, p. 71. 
constantemente ${ }^{32}$. Si bien estas interpretaciones parecen adecuadas para las obras de madurez de Diderot, está versión moderada del pesimismo histórico parece no agotar el tratamiento del tema de la historia en su filosofía.

\section{La historia, el escepticismo y el progreso}

Elisabeth de Fontenay sostiene que Diderot estuvo “a veces más cerca de Montaigne y de Nietzsche que de sus contemporáneos"3.3. Inmediatamente añade que "las grandes figuras de sus escritos -el sobrino de Rameau, la religiosa, los ciegos de nacimiento, los sordomudos, el matemático delirante, los salvajes, las mujeres-, socavan la pretensión del sujeto occidental y masculino de erigirse como pilar de un saber neutro y de un poder soberano" 34 . Si bien es verdad que de las páginas de Jacques le fataliste et son maître o Le neveu de Rameau parece emanar un aire nietzscheanoderridiano, Diderot no fue un escéptico en el sentido fuerte del término ${ }^{35}$.

La relación que mantuvo con los trabajos de Pierre Bayle, uno de los padres del escepticismo moderno ${ }^{36}$, sustenta esta afirmación. En uno de los primeros volúmenes de la revista Diderot Studies, Norman Torrey dice que

\footnotetext{
32 Krakeur, Lester, op cit., p. 158.
}

33 Fontenay, Elisabeth, Diderot o el materialismo encantado, trad. cast. Angelina del Campo, Fondo de Cultura Económica, México D.F., 1988, p. 14. Sobre la relación Diderot-Nietzsche, véase Schober, Angelika, "Diderot et Nietzsche", en Diderot Studies, $\mathrm{N}^{\circ} 25,1993$, pp. 91 y ss.

${ }^{34}$ Ibid., p. 15.

35 Para una lectura en sentido contrario, véase Le $\mathrm{Ru}$, Véronique, "Le scepticisme dans l'Encyclopédie de Diderot et de d'Alembert", Revue de métaphysique et de morale, $\mathrm{N}^{\circ}$ 65, 2010, pp. 75-92.

${ }^{36}$ Sobre el escepticismo de Pierre Bayle puede consultarse Popkin, Richard Henry, The History of Scepticism: from Savonarola to Bayle, Oxford University Press, Oxford, 2003, pp. 283 y ss. Hay una traducción al castellano de una selección de artículos del Diccionario bistórico y crítico de Bayle (edición, traducción, prólogo y notas de Fernando Bahr, Buenos Aires, El cuenco del plata, 2010). 
Pierre Bayle fue uno de los precursores de Diderot ${ }^{37}$. Sin duda el Dictionnaire historique et critique de Bayle fue una obra de referencia para todos los filósofos ilustrados y Diderot no fue la excepción. Sin embargo, una importante distancia separa el Dictionnaire de Bayle de la Eincyclopédie.

Diderot dice, en el artículo "eclectisme" de la Encyclopédie, que el eclecticismo es la filosofía de todos los grandes pensadores, entre los que ubica a Bacon, Leibniz, Hobbes, Descartes. Bayle no es mencionado. La influencia de Jakob Brucker sobre Diderot fue seguramente determinante en este punto $^{38}$. Diderot recurre a Brucker para redactar la parte de la Encyclopédie dedicada a la historia de la filosofía. En su Historia critica philosophiae a mundi incunabulis ad nostram usque aetatem deducta, Brucker afirma que la historia de "la filosofía se confunde con la historia del espíritu humano" y que debería mostrar el desenvolvimiento de ese espíritu, su surgimiento, sus progresos y los obstáculos que han detenido parcialmente su marcha ${ }^{39}$. En esa historia Bayle no ocupa un lugar importante, por el contrario es colocado entre los filósofos sectarios, es decir, entre los espíritus perdidos para la buena filosofía.

Pero, la omisión del nombre de Bayle entre los grandes pensadores no se explica sólo a partir de la influencia de Brucker. La causa hunde sus raíces en lo más profundo del pensamiento de Diderot. Ya en los capítulos XXII, XXIV y XXX de sus tempranos Penseés philosophiques Diderot diferencia al "ateo verdadero" del "ateo escéptico" y al "escéptico" del "pirrónico". Diderot distingue entre el escepticismo como metodología y el escepticismo metafísico. Como bien señala Jean-Claude Bourdin, Diderot

${ }^{37}$ Torrey, Norman, "Introduction", en Diderot Studies, N 3, 1961, p. 11.

${ }^{38}$ Acerca de la relación entre Diderot y Brucker, véase Retat, Pierre, Le Dictionnaire de Bayle et la lutte philosophique au YVIIIe siècle, Paris, Société d'Edition Les Belles Lettres, 1971, p. 389; Proust, Jacques, Diderot et l'Encyclopédie, Armand Collin, Paris, 1962, pp. 233 y ss.

${ }^{39}$ Cfr. Brucker, Jakob, The History of Philosophy, trad. al inglés por William Enfield, J. Johnson, Londres, vol. 1, 1791, p. 7. 
no aceptó nunca este último tipo de escepticismo ${ }^{40}$. En un trabajo de 1747 , La promenade du sceptique, se queja amargamente de aquellos que niegan que exista otra cosa que las impresiones ${ }^{41}$. En este libro el viajero pone en cuestión una gran cantidad de sectas filosóficas, sin embargo no llega al extremo de aceptar el escepticismo radical, el escepticismo de todos aquellos que creen "que no hay ni jardín, ni árboles, ni viajeros; que todo lo que uno ve podría ser otra cosa, o podría no ser nada" 42 .

Para Diderot el escepticismo extremo conduce hacia el idealismo, una negación solipsista de la realidad. Podía aceptar el escepticismo como herramienta metodológica en el camino hacia el conocimiento, pero no como posición metafísica. El escepticismo es sin dudas, dice, "el primer paso hacia la verdad" 43 . El pirronismo, en cambio, es a sus ojos la negación de la realidad, de la verdad. "No escucharé más a aquellos que niegan la existencia de los cuerpos, las reglas de la lógica, el testimonio de los sentidos, la distinción de lo verdadero y lo falso, del bien y el mal, del placer y la pena, del vicio y la virtud, de lo decente y lo indecente, de la justicia y la injusticia, de lo honesto y lo deshonesto", dice Diderot en la entrada "Pyrrhonienne ou sceptique" de la Encyclopédie 44 . Con el mismo espíritu en la voz "Scepticisme ou sceptiques", define a los escépticos como una "secta de viejos filósofos que tenían a Pirrón por jefe, y cuyo dogma principal era que todo era incierto e incomprensible, que los contrarios eran igualmente verdaderos" 45 .

40 Cfr. Bourdin, Jean-Claude, "Matérialisme et scepticisme chez Diderot", en Recherches sur Diderot et sur l'Encyclopédie, N²6, 1999, p. 85.

${ }^{41}$ Cfr. Diderot, Denis, La pronienade du sceptique, en A-T., vol. I, 1875, p. 216.

42 Ibidem.

${ }^{43}$ Diderot, Denis, Penseés philosophiques, en A-T., vol. I, 1875, p. 140.

${ }^{44}$ Diderot, Denis, "Pyrrhonienne ou sceptique", en Diderot, Denis; D'Alembert, Jean le Rond (eds.), Encyclopédie ou Dictionnaire raisonné des sciences, des arts et des métiers par une société des gens de lettres, Briasson, David, Le Breton, Durand, Paris, vol. XIII, 1765 , p. 614.

45 Ibid., vol. XIV, 1765, p. 756. 
Incluso en una obra tardía como el Essai sur les règnes de Claude et de Néron, se pregunta cómo "Parménides pudo pensar que nada de lo que vemos existe, y Zenón, que no existe nada". Estas cosas representan, para Diderot, una "vergüenza para la razón humana" 46.

Cabe entonces la pregunta por el tipo de conocimiento que Diderot rescata de la marea escéptica. En este punto es clave la influencia de Francis Bacon sobre Diderot ${ }^{47}$. "Si salimos con éxito [de esta empresa], estaremos en deuda principalmente con el canciller Bacon"48, dice Diderot en el Prospectus que escribió en 1750 para la Encyclopédie y que fue incluido con algunas modificaciones en el primer volumen de la misma publicado, en 1751, al final del Discours preliminaire de D'Alembert. En el artículo "Art" Diderot dice que “jamás dejará de leer a Bacon” y en el artículo "Encyclopédie" se jacta de haber introducido a Bacon en Francia"4.

Lejos de las Summae escolásticas y de los grandes sistemas filosóficos omniabarcativos, el autor del Novum Organum ofrece a Diderot un modelo epistemológico dinámico, en el que el saber como un edificio se va levantando poco a poco ${ }^{50}$. El conocimiento no es un dato, sino algo incompleto que se perfecciona con el correr de los siglos. El conocimiento

${ }^{46}$ Diderot, Essai sur les règnes de Claude et de Néron, ed. cit., p. 257. Cfr. Chouillet, Jacques, "Le personnage du sceptique dans les premières œuvres de Diderot (17451747)", en Dix-buitième siècle, vol. 1, 1963, p. 210.

47 Acerca de la influencia de Francis Bacon sobre Diderot, véase Dieckmann, Herbert, "The Influence of Francis Bacon on Diderot's Interprétation de la Nature", The Romanic Review, n 34, 1943, pp. 303-330; Wilson, Arthur, op. cit., pp. 158 y ss.

48 Diderot, Denis, Prospectus, en A-T., vol. XIII, 1876, p. 133.

${ }^{49}$ Cfr. Diderot y D’Alembert (eds.), Encyclopédie, ed. cit., vol. V, 1755, p. 647. Cabe señalar que ya en 1734 Voltaire había mencionado a Bacon en sus Lettres ploilosopbiques.

50 Cfr. Malherbe, Michel, "Bacon, Diderot et l'ordre encyclopédique", Revue de Synthèse, $\mathrm{n}^{\circ} 1-2,1994$, p. 26. Para una visión de conjunto respecto de la concepción de la historia de Francis Bacon, véase Taguieff, Pierre, Le sens du progrès. Une approche bistorique et philosophique, Flammarion, Paris, 2004, pp. 148 y ss. 
es a sus ojos un gran edificio que el hombre, débil y limitado, va levantando irregularmente.

En esta parte de la obra de Diderot el tiempo es progresivo, no es algo fijo, no es una eterna repetición de lo mismo. Sobre esta idea del tiempo se apoya la Encyclopédie. En este marco la Encyclopédie debe contribuir con la mirada puesta en el futuro, a la edificación del conocimiento. El objetivo de la misma, dice Diderot, es "reunir todo el saber disperso en la superficie de la tierra, para describir el sistema general a las personas con quienes vivimos, y transmitirlo a aquellas que vendrán después de nosotros para que el trabajo de los siglos pasados no sea inútil para los siglos futuros, y que nuestros descendientes, haciéndose más ilustrados, puedan ser más virtuosos y más felices" 51 .

Para escribir una enciclopedia, dice Diderot, es necesario "conocer el espíritu de la nación, advertir su rumbo, ganarle en velocidad, de manera que no deje atrás vuestro trabajo". Es necesario, dice, que una enciclopedia se adelante todo lo posible, para no ser rápidamente sobrepasada por el "espíritu nacional" que "camina sin cesar".

Por otro lado, poniendo el acento en la incompletitud del conocimiento señala en el Prospectus que D'Alembert y él son conscientes de las carencias de la Encyclopédie y que "la perfección de una enciclopedia es la obra de los tiempos"52. Asimismo en el Avertissement al volumen octavo de la Encyclopédie se puede leer: "Gracias a nuestros trabajos, los que vengan después de nosotros podrán ir más lejos" ${ }^{53}$.

Diderot afirma en la Encyclopédie que el progreso es un "camino trazado" de donde el hombre no puede alejarse. Puntualmente en el artículo "Eclectisme" habla de "la ruta que sigue naturalmente el espíritu humano en sus progresos" 54 . Es sobre esta base que intenta "formar un cuadro

${ }^{51}$ Diderot y D’Alembert (eds.), Encyclopédie, ed. cit., vol. V, 1755, p. 635.

52 Ibid., p. 144.

${ }^{53}$ Diderot, Denis; D’Alembert, Jean le Rond (eds.), Encyclopédie, ed. cit., vol. VIII, "Avertissement".

${ }^{54}$ Ibid., vol. V, p. 283. 
general de los esfuerzos del espíritu humano en todos los géneros y en todos los siglos" 55 . En este marco se ubican los innumerables artículos de la Encyclopédie dedicados a las artes manuales y los 11 volúmenes de láminas publicados entre 1762 y 1772 . No se trata de un catálogo para artesanos, sino de la obra de un intelectual que, como señala Jacques Proust, ha intentado discernir en el vasto panorama de las fuerzas productivas de su tiempo, esas que iban en el sentido del progreso ${ }^{56}$. Como bien señala Proust no eran los sucesos aislados lo que interesaba a Diderot, sino "la historia de los progresos del espíritu humano y de sus producciones" 57 .

Pero el optimismo que se desprende de esta parte de la obra de Diderot no es igual al que años más tarde impregnaría el Esquisse d'un tableau bistorique des progres de l'esprit bumain de Condorcet ${ }^{58}$. En el ya mencionado artículo "Encyclopédie" Diderot dice: "los conocimientos se expanden día a día. No hay mujer con cierta educación que no emplee con discernimiento todas las expresiones consagradas a la pintura, a la escultura, a la arquitectura y a las bellas artes. ¡Cuántos niños tienen la intención de conocer estas cosas, cuántos niños saben geometría, cuantos niños son músicos (...)!" 59. Sin embargo, agrega, "los conocimientos no se expanden más que hasta cierto punto (...) las revoluciones son necesarias, siempre las bubo y siempre las babra'"60. Diderot entiende que las sombras nunca desaparecen

${ }_{55}$ Diderot, Denis, Prospectus, ed. cit. p. 130.

${ }^{56}$ Cfr. Proust, Jacques, op. cit., p. 507.

57 Ibid., p. 508.

${ }^{58}$ Cabe señalar que en los últimos años la interpretación canónica de la obra de Condorcet, aquella según la cual en sus trabajos la idea de progreso habría alcanzado su más alta expresión, ha sido cuestionada, véase Loty, Laurent, "Condorcet contre l'optimisme: de la combinatoire historique au meliorisme", en Crepel, Pierre; Gilain, Christian (eds.), Condorcet mathematicien, economiste, philosophe, bomme politique, Minerve, Paris, 1988, pp. 288-296; Waldinger, Renee, "Condorcet: The Problematic Nature of Progress", in Condorcet Studies, I, 1984, pp. 117-129.

${ }^{59}$ Diderot y D’Alembert (eds.), Encyclopédie, ed. cit., vol. V, 1755, p. 636.

${ }^{60}$ Ibid., p. 637 (las cursivas son nuestras). 
completamente ${ }^{61}$, una porción de la tierra volverá a "recaer en las tinieblas", dice. Asimismo en el artículo "Eclectisme", donde habla de la "ruta que sigue el espíritu humano en sus progresos", dedica un largo párrafo a la descripción de aquello que frena y retarda los progresos de las ciencias y las artes: las "disputas teológicas" y "la intolerancia producto de la superstición". Cléobule nos recuerda en la Promenade du sceptique que esclarecer a los hombres es "la tarea más importante que uno puede proponerse, pero es al mismo tiempo algo que no sucederá jamás" 62 . Esto no implica no obstante una postura pesimista, ya que como dice en una carta de 1766, las luces pueden cambiar de lugar, pero no pueden extinguirse. Quizá sean las palabras que Constance dirige a Dorval en Le fils naturel las que mejor representan esta compleja filosofía de la historia: "Sin duda hay aún bárbaros. ¿Dejará de haberlos en algún momento? Pero los tiempos de la barbarie han pasado"63.

${ }^{61}$ En el artículo "Perfectionner", Diderot dice que la razón nunca llegará a dominar los "despóticos" deseos del corazón: "El hombre está compuesto por dos órganos principales, la cabeza, órgano de la razón, el corazón, expresión bajo la cual se comprenden todos los órganos de las pasiones, el estómago, el hígado, los intestinos. La cabeza en el estado de naturaleza no influye casi nada sobre nuestras determinaciones. El corazón es el principio; a partir del corazón el hombre hizo todo. Es el arte quien ha perfeccionado el órgano de la razón, todo lo que éste es, es artificial. No tenemos el mismo poder sobre el corazón, es un órgano obstinado, sordo, violento, apasionado, ciego. Éste permanece a pesar de nuestros esfuerzos tal como la naturaleza lo ha hecho, duro, sensible, débil, indomable, pusilánime y temerario. El órgano de la razón es como un preceptor atento que lo controla sin cesar, el corazón es como un infante, llora continuamente, cansa a su preceptor que finalmente lo abandona. El preceptor es elocuente, el infante en cambio no conoce más que una palabra que repite sin cesar. Llega un tiempo en el que el órgano de la razón cansado de los bellos discursos e instruido por la experiencia acerca de la inutilidad de su elocuencia, se burla de sí mismo y de sus esfuerzos, puesto que sabe que a pesar de todas sus amonestaciones el pequeño déspota no hará más que lo que le plazca”, en Diderot y D’Alembert (eds.), Encyclopédie, ed. cit., vol. XII, 1765 , p. 352.

${ }^{62}$ Diderot, Denis, La promenade du sceptique, ed. cit., p. 181.

${ }^{63}$ Diderot, Denis, Le fils naturel, en A-T., vol. VII, 1875, p. 78. 


\section{La "disputa sobre la posteridad"}

En los años 60' se produce un intercambio epistolar entre Diderot y Falconet que luego fue conocido como la "Dispute sur la posterité" 64. Falconet negaba en su correspondencia que el genio del artista tuviese necesidad de la posteridad para desarrollarse. Diderot convierte la discusión en una controversia sobre el sentido de la historia. En ese intercambio epistolar se escucha el eco del optimismo de Diderot en los años anteriores a su viaje a Rusia.

El concepto de "posteridad", que ya había sido utilizado numerosas veces por el editor de la Encyclopédie, le permite inscribir su lucha contra los tiranos y los sacerdotes en el marco de un proceso que asegura el triunfo de las luces. En una de las cartas exclama:

Las luces pueden cambiar de lugar pero no pueden apagarse. $\mathrm{Y}$ los tiranos y los sacerdotes, y todos aquellos que tienen algún interés en mantener a los hombres en el estado de ignorancia se estremecen de rabia. Es un sueño inestra posteridad... No es un sueño, o las esperanzas fundadas en el mérito de nuestras producciones, o la comparación de nuestras producciones con las de los antiguos, o el elogio que nuestros contemporáneos hacen de unos y de otros, o las luces y el buen gusto de estos hombres, o las luces y el buen gusto de los demás artistas (...), o todo eso que puede garantizar en la actualidad a un hombre hábil el éxito y la duración de su obra, son también sueños ${ }^{65}$.

${ }^{64}$ Ese fue el título que utilizó Falconet en un borrador de la correspondencia. La correspondencia fue publicada recién en 1958 por Yves Benot (Le Pour et le Contre. Correspondance polémique sur le respect de la posterité, Paris, Editeurs Français Réunis, 1958) y en 1959 por Herbert Dieckmann y Jean Seznec (Diderot et Falconet. Correspondance: les six premières lettres, Frankfurt, Klostermann, 1959). Acerca de este intercambio epistolar, véase Posadas, Maurice, "An Introduction to the Textual Problem of the Diderot-Falconet Correspondence on Posterity", en Diderot Studies, $\mathrm{n}^{\circ} 16,1973$, pp. 175-196.

${ }^{65}$ Diderot, Denis, Correspondance, en A-T., vol. XVIII, 1876, p. 99. 
Pensando en aquellos hombres esclarecidos que han sido perseguidos por "pueblos estúpidos, sacerdotes atroces, tiranos furiosos", afirma que "el prejuicio pasará y la posteridad arrojará la deshonra sobre sus enemigos". Inmediatamente agrega una especie de oración a la posteridad: "iOh posteridad santa y sagrada!" 66 .

Como bien señala Marc Buffat, Diderot tomando distancia de la mirada apocalíptica de Falconet enlaza el presente y el futuro, cree que las obras de artes pasarán a la posteridad y que si son destruidas subsistirá su memoria a través de los textos que hablen de ellas ${ }^{67}$. Sin embargo, Diderot no es ingenuo, acepta que la marcha de la razón no es lineal, que las sombras son siempre una amenaza ("las luces pueden cambiar de lugar"). Pero no es pesimista, sabe que los logros de la civilización no se extinguen: "Superponed suposición sobre suposición, acumulad guerra sobre guerra, a disturbios interminables haced suceder otros disturbios interminables, arrojad sobre el universo un espíritu de vértigo y confusión, y yo os doy cien mil años para perder las obras y el nombre de Voltaire, vosotros no podréis más que alterar la pronunciación de su nombre" 68 .

Diderot desespera cuando escucha a Falconet hablar de "grandes hombres olvidados" o "grandes obras perdidas o destruidas" 69 . Se le objeta que las bibliotecas se incendiarán tarde o temprano, a lo cual responde: "El fuego caerá algún día en la Biblioteca Real. Un día las nubes de humo y el fuego dispersarán en el aire las cenizas y las páginas de los antiguos y de los modernos. Una pena por el público, por la nación, por el monarca, pero Homero, Virgilio, Corneille, Racine, Voltaire, no sufrirán ningún daño. Sus obras se continuarán leyendo en cien lugares de la tierra en el momento

66 Ibidem.

67 Buffat, Marc, "Diderot, Falconet et l'amour de la postérité", en Recherches sur Diderot et sur l'Encyclopédie, $\mathrm{N}^{\circ}$ 43, 2008, p. 19. Para Diderot, dice Buffat, la "posteridad" es algo "material", no es una simple representación mental.

${ }^{68}$ Diderot, Denis, Correspondance, ed. cit., p. 99.

69 Ibid., p. 98. 
mismo del incendio"70. Esto se debe, dice, "al progreso del espíritu humano y al arte de Fournier"71.

\section{Consideraciones finales}

En el libro Lumières de l'utopie Bronislaw Baczko asocia la idea de progreso de les philosophes a la utopía. Baczko encuentra en el siglo XVIII francés los comienzos de un proceso a través del cual se integran los viejos discursos utópicos a una filosofía sobre el porvenir, es decir, un proceso donde se acoplan utopía, historia y progreso. En el Siècle des Lumières, dice, comienza "la fusión de imágenes utópicas y de un discurso histórico en un discurso global y en un relato mítico acerca de la historia-progreso"72. Baczko habla del "reencuentro que se realiza en el siglo XVIII entre la utopía y la idea de progreso"73. Todo el libro tiene como objetivo mostrar el cruce entre historia y utopía en el Siècle des Lumières, "luces de la utopía, utopía de las luces", dice Baczko ${ }^{74}$.

Baczko se acerca de esta manera a las interpretaciones que desde el mismo siglo XVIII atribuyen a les philosophes una idea de la historia ingenua, abstracta y desarraigada de lo real. En los últimos años, por el contrario han visto la luz una serie de trabajos que avanzan en sentido contrario ${ }^{75}$. Florence Lotterie no duda en afirmar en uno de sus trabajos que "el siglo de las Luces permance tributario del esquema de la decadencia"76; Frank

${ }^{70}$ Ibid., p. 105.

\section{Ibidem.}

${ }^{72}$ Baczko, Bronislaw, Lumières de l'utopie, Paris, Payot, 2001, p. 174.

${ }^{73}$ Ibid., p. 153.

${ }^{74}$ Ibid., pp. 7, 8.

${ }^{75} \mathrm{El}$ ya mencionado trabajo de Henry Vyverberg, Historical Pessimism in the French Enligbtenment (1958), ha sido una referencia obligada para aquellos que se alinean detrás de esta nueva corriente interpretativa.

${ }^{76}$ Cfr. Lotterie, Florence, "L'année 1800: Perfectibilité, progrès, et révolution dans De la littérature de Mme de Staël", en Romantisme, No 108, 2001, pp. 9-22. De manera similar se expresa en trabajos como "Les Lumières contre le progrès ? La naissance de l'idée de perfectibilité", en Dix-buitième siècle, N³0, 1998, pp. 383-96, 
Edward Manuel y Fritzie Prigohzy Manuel señalan que la mayoría de los philosophes estaban "convencidos de que a las épocas de florecimiento seguían de manera recurrente períodos de decadencia"77, y Jean-Marie Goulemot en Le Règne de l'bistoire. Discours historique et révolutions XVIIeXVIIIe siècles dice, luego de hablar de la "nostalgia de los orígenes", del discurso de la decadencia y la fascinación por las ruinas en el siglo XVIII, que "el pesimismo histórico domina la época"78.

Como se desprende de este trabajo ninguna de estas interpretaciones generales logra dar cuenta de la filosofía de la historia de Diderot. Por una parte, la confianza en el futuro que se desprende de los trabajos anteriores al viaje a Rusia, los tiempos de la Encyclopédie, desborda la interpretación "pesimista". Por otra parte, la interpretación de aquellos que atribuyen a les philosophes una imagen ingenua, utópica de la historia no logra dar cuenta en primer lugar del desencanto de las obras de madurez, en segundo lugar de la prudencia, de las reservas de Diderot respecto del futuro en los tiempos mismos de la Encyclopédie.

Recibido 12/2010; aceptado 06/2011.

y Progrès et perfectibilité: un dilenme des Lumières franşaises (1755-1814), Studies on Voltaire and the Eighteenth Century, Oxford, 2006, p. XXI.

77 Manuel, Frank; Manuel, Fritzie, Utopian Thought in the Western World, Harvard University Press, Cambridge, 1979, p. 414.

${ }^{78}$ Goulemot, Jean-Marie, Le Regne de l'bistoire. Discours historique et révolutions XVIIeXVIIIe siècles, Albin Michel, Paris, 1996, p. 391. 